\title{
SISTEM INFORMASI PEMESANAN TIKET BUS PADA CV. CHANDRA BAGAN BATU BERBASIS WEB
}

\author{
Arif Rahmad Hidayat ${ }^{1)}$, Volvo Sihombing ${ }^{2)}$ Deci Irmayani ${ }^{3)}$ \\ 1,2,3Fakultas Sains dan Teknologi, Universitas Labuhanbatu \\ email: arifrahmad21@gmail.com,volvolumbantoruan@gmail.com,deacyirmayani@gmail.com
}

\begin{abstract}
CV. Bus Chandra Bagan batu, is a service company engaged in the transportation sector. The method used by CV. Bus Chandra Bagan batu to order tickets, customers must come to the counter to order tickets. This makes it difficult for people to order tickets, especially if the weather is not supportive. So this bus ticket booking information system was created which aims to make it easier for customers to order bus tickets at CV.Bus Chandra. This information system is built using the PHP programming language and MySQL database and is supported by the local Xampp server. Through this information system, customers will find it easier to order bus tickets at CV. Bus Chandra Bagan batu.
\end{abstract}

Keywords: Ticket Booking, PHP, MySQL, Bus

\section{PENDAHULUAN}

Perkembangan zaman sangat mempengaruhi teknologi informasi, saat ini teknologi informasi semakin berkembang pesat dan telah mempengaruhi kehidupan semua manusia [1]. Dengan berkembangnya teknologi informasi, telah merubah pola berorganisasi, berbisnis dan menjalankan aktifitas lainnya. Semakin banyak manusia yang menggunakan teknologi semakin banyak pula media komunikasi yang bisa mengaksesnya dan semakin membuka peluang usaha bagi perusahaan untuk mengembangkan bisnis,relasi,dan pelayanan sebagai sarana untuk memperkenalkan perusahaan kepada pelanggan. Untukmeraih pelanggan banyak persaingan yang terjadi terutama dalam penyediaan layanan transportasi, beberapa penyedia layanan transportasi telah memanfaatkan teknologi untuk meningkatkan pelayanan kepada pelanggan.

CV. Chandra merupakan penyedia layanan transportasi. Pada saat ini layanan penjualan tiket pada $\mathrm{CV}$. Chandra masih menggunakan cara konevnsional yakni setiap pelanggan harus datang ke loket bus tersebut. Metode konevnsional yang berjalan saat ini masih kurang efektif untuk menjangkau pelayanan terhadap penumpang.

Seiring dengan perkembangan teknologi, pihak $\mathrm{CV}$. Chandra ingin mengembangkan pelayanan agar masyarakat dapat lebih mudah membeli tiket. Oleh karena itu dirancang sebuah sistem berbasis komputer yang dapat membantu mempermudah $\mathrm{CV}$. Chandra dalam melayani penumpang.

Saat ini pemanfaatan teknologi informasi telah digunakan pada banyak hal, baik dalam bidang pendidikan, usaha penjualan barang, sekolah, pemerintahan, dan sebagainya [2]-[11], [12]-[14]. Dengan pemanfaatan teknologi maka CV. Chandra dapat memperkenalkan jasa pada pelanggan, sehingga dapat meningkatkan pleyanan dan kepuasaan pelanggan.

Berdasarkan masalah tersebut maka dilakukan perancangan sistem informasi pemesanan tiket bus berbasis web untuk memudahkan informasi yang berhubugan dengan CV. Chandra sehingga dapat menciptakan efektifitas dan efesiensi dalam hal pemasaran dan pelayanan kepada pelanggan.

\section{METODE PENELITIAN}

\subsection{Metode Pengumpulan Data}

Untuk membantu $\begin{array}{r}\text { penyelesaian } \\ \text { permasalahan dalam }\end{array}$
perancangan sistem ,maka mengaikan
beberapa teknik pengumpulan data yaitu:
1. Studi Literatur


Dalam studi literatur yaitu mengumpulkan datadata dengan menggunakan buku, jurnal, artikel maupun referensi lainnya yang berhubungan dengan materi yang di bahas dalam penulisan tugas akhir ini.

\section{Teknik Observasi}

Dalam teknik Observasi yaitu mengadakan penelitian dengan mengamati secara langsung keloket CV.bus chandra bagaimana cara memesan tiket pada CV.Chandra.

\section{Teknik Wawancara}

Pada teknik wawancara yaitu mengadakan penelitian dengan mewawancarai admin loket chandra yang pada saat itu dirut loket bus Chandra

\subsection{Perancangan Sistem}

\subsubsection{DFD (Data Flow Diagram}

Data Flow Diagram Context Level merupakan bagan bagian dari DFD yang berfungsi memetakan atau memberikan gambaran model lingkungan yang dihasilkan dengan lingkungan tunggal yang mewakili keseluruhan sistem. DFD Context Level ini juga disebut dengan Context Diagram [15].

DFD dari Sistem informasi penjualan tiket pada CV. Chandra dapat dilihat pada gambar 1.

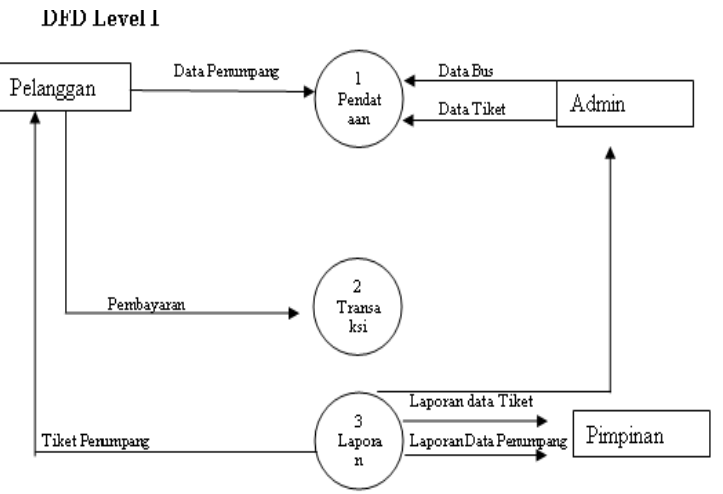

Gambar 1. DFD Level 1 Penjualan Tiket

Entity Relationship Diagram digunakan dalam membangun basis data untuk menggambarkan relasi atau hubungan dari dua file atau dua tabel dalam sistem E-Commerce yang akan dirancang[16][10] dapat dilihat pada sistem yang akan di rancang pada sistem informasi pemesanan tiket bus berbasis web adalah sebagai berikut adalah sebagai berikut:

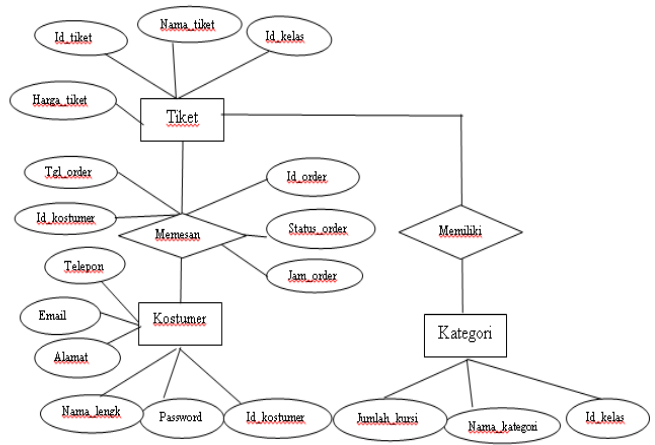

Gambar 2. ERD Sistem Penjualan Tiket

Relasi antar Tabel dalam penelitian penjualan tiket adalah seperti gambar 3 .

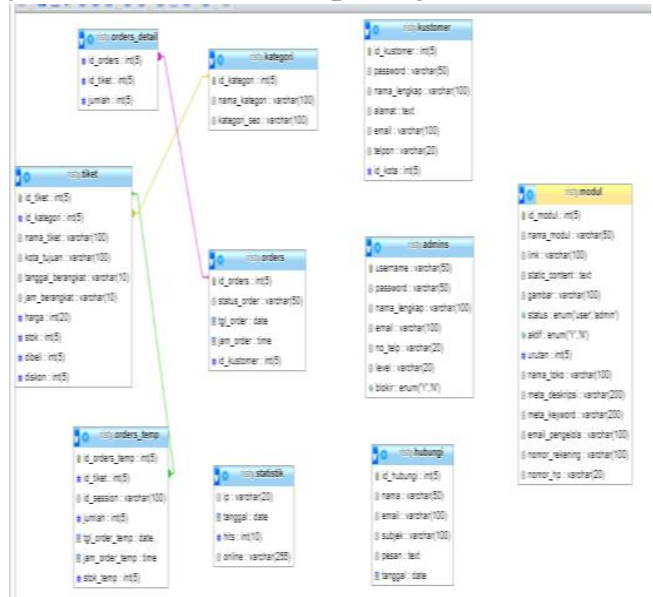

Gambar 3. Relasi Antar Tabel Penjualan Tiket

\subsubsection{Flowchart}

Flowchart (bagan alir) adalah ("gambaran dalam bentuk diagram alir dari algoritmaalgoritma dalam suatu program, yang menyatakan arah alur program tersebut") [17].

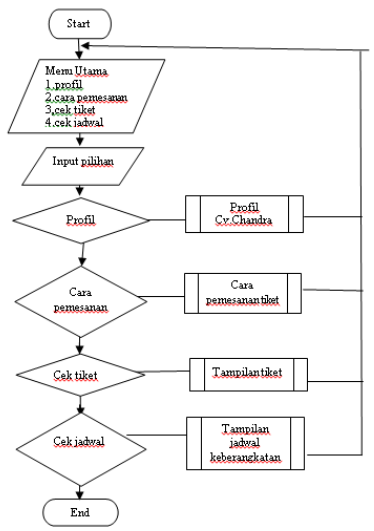

Gambar 4. Flowchart Penjualan Tiket 


\section{HASIL DAN PEMBAHASAN}

Adapun hasil tampilan eksekusi program meliputi menu, form input sistem, dan report (output sistem) yang akan di bahas sebagai berikut

\subsection{Menu}

\section{Halaman Depan}

Gambar di bawah ini merupakan tampilan awal dari sistem informasi Pemesanan Tiket Bus Pada CV. Chandra Bagan batu.

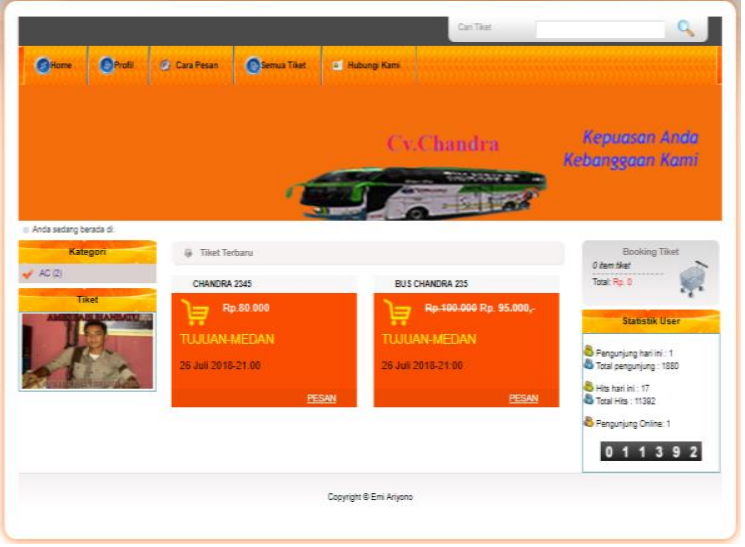

Gambar 5. Halaman Utama

\subsection{Masukan (Input) Sistem}

Halaman login ini digunakan admin untuk menjalankan atau mengelola suatu program agar program tersebut dapat berjalan dengan baik. Pada sistem yang di bangun menggunakan username admin dan password admin apabila password dan username tidak sesuai maka akan ada pemberitahuan "maaf username dan password salah"

Gambar dibawah ini merupakan login untuk menjalankan program.

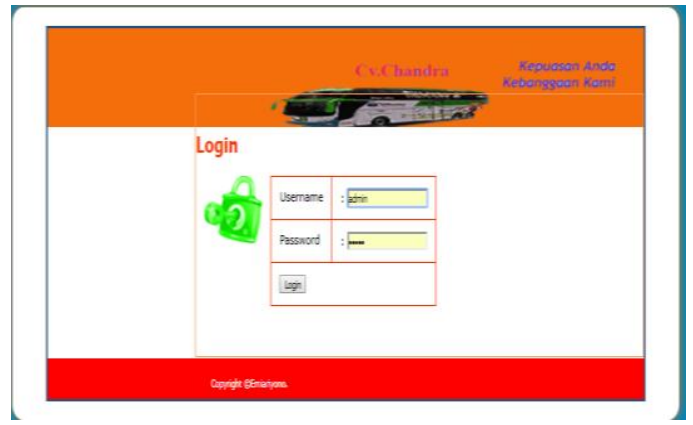

Gambar 6. Halama Login

\subsection{Halaman Input Data Penumpang}

Halaman ini tempat untuk pelanggan mengisi data diri yang terdiri dari nama penumpang, password, alamat, nomor telepon penumpang email penumpang. Apabila penumpang tidak mengisi semua kolom maka penumpang tidak dapat memesan tiket.

Gambar dibawah ini merupakan input data penumpang.

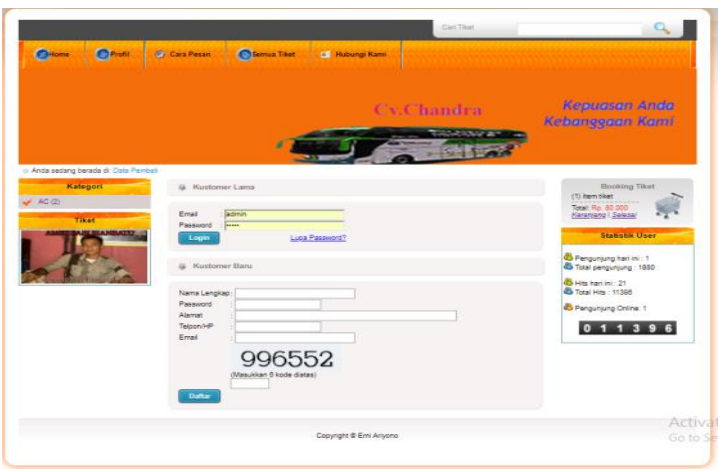

Gambar 7. Data Penumpang

\subsection{Input Data Tiket}

Halaman Input Data tiket hanya bisa di lakukan oleh admin. Untuk mengisi data tiket admin harus mengisi beberapa kolom yang tersedia di antaranya kolom nama bus, kategori bus, tujuan, jam berangkat, tanggal berangkat dan kursi tersedia. Semua kolom harus terisi dan tak boleh kosong.

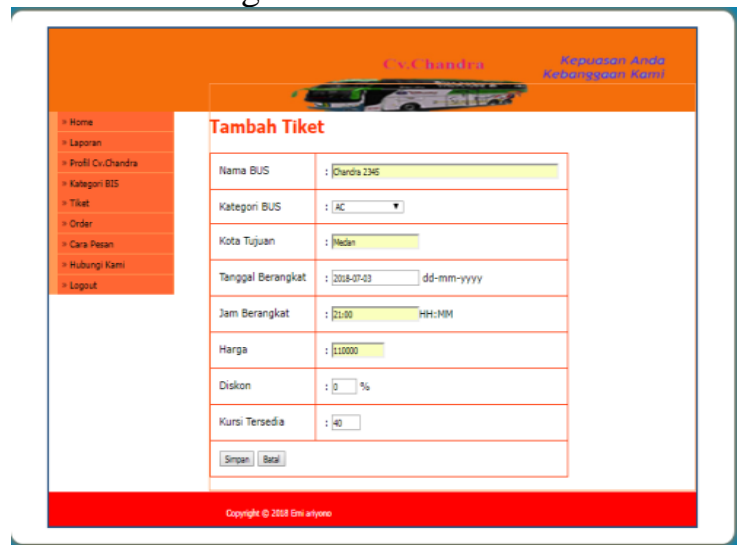

Gambar 8. Input Tiket Bus Chandra

\subsection{Keluaran (Output) Sistem}

Tahap yang merupakan proses menghasilkan output dari hasil pengolahan data ke alat output (output device), yaitu berupa informasi. Laporan Data Pemesanan Tiket Laporan pemesan tiket ditujukan kepada 
pimpinan perusahaan dan di buat oleh petugas penjaga CV.Chandra cabang bagan batu.

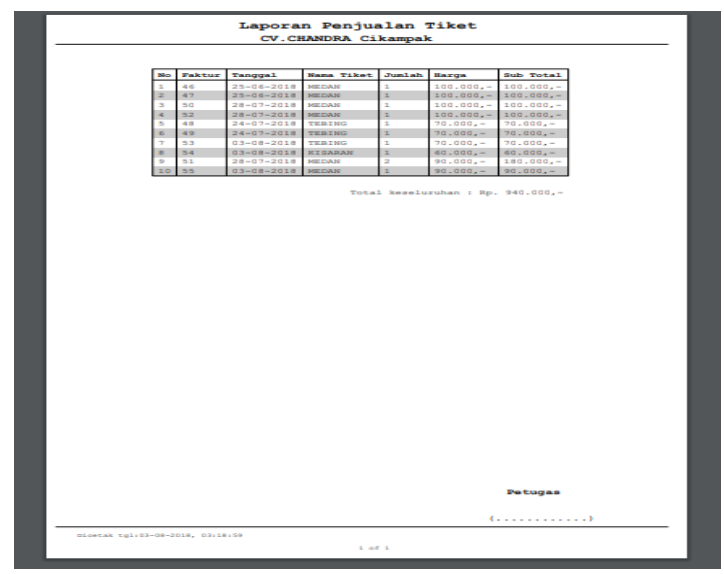

Gambar 9. Laporan Pemesanan Tiket

Pada bagian ini berisikan Laporan atau output dari sistem, setiap output dan laporan harus dijelaskan fungsi penggunaanya dan kelebihannya.

Pada sistem ini penumpang harus mendaftar terlebih dahulu sebelum memesan tiket, kemudian setelah dapat persetujuan dari admin dan telah melakukan pembayaran pelanggan baru dapat mencetak bukti pembayaran.

\section{KESIMPULAN}

Kesimpulan yang dapat diambil berdasarkan hasil analisis dan pembahasan yang sedang berjalan dan rancangan sistem adalah sebagai berikut:

1. Bahwasannya komputerisasi sangat diperlukan dalam pengolahan data tiket pada CV.Chandra bagan batu tersebut yang sebelumnya dilakukan secara manual karena dapat meningkatkan efektifitas dan efesiensi pengolahan pemesanan tiket.

2. Adanya program aplikasi ini semua data yang bersangkutan dengan pengolahan data pemesanan tiket dapat terjaga, keefektifan serta keefesienan waktu dapat tercapai dengan baik, karena program aplikasi ini merupakan penyederhanaan dari bentukbentuk dokumen atau media pengolahan data secara manual berupa kertas-kertas menjadi file-file yang tersimpan dalam media penyimpanan di dalam komputer.

3. Pembuatan laporan serta pengolahan data tiket dapat dihasilkan secara baik, mudah, cepat dan akurat.

\section{REFERENSI}

[1] J. D. Raharjo, R. Tullah, and H. Setiana, "Sistem Informasi Pemesanan Dan Pembelian Tiket Bus Online Berbasis Web Pada P.O. Budiman," Sisfotek Glob., vol. 9, no. 2, pp. 120-125, 2019.

[2] V. Sihombing and G. J. Yanris, "PENERAPAN APLIKASI DALAM MENGOLAH ASET DESA (STUDI KASUS: KEPENGHULUAN SRI KAYANGAN)," J. Mantik Penusa, vol. 4, no. 1, pp. 12-15, 2020.

[3] J. Simatupang, "Perancangan Sistem Inventori Barang pada Toko Nichos Jaya Menggunakan Metode FIFO," J. Intra Tech, vol. 1, no. 1, pp. 31-42, 2017.

[4] J. Simatupang and S. Sianturi, "PERANCANGAN SISTEM INFORMASI PEMESANAN TIKET BUS PADA PO. HANDOYO BERBASIS ONLINE," J. Intra Tech, vol. 3, no. 2, pp. 11-25, 2019.

[5] Fricles Ariwisanto Sianturi, "Analisa metode teorema bayes dalam mendiagnosa keguguran pada ibu hamil berdasarkan jenis makanan," Tek. Inf. dan Komput., vol. 2, no. 1, pp. 87-92, 2019, [Online]. Available: http://jurnal.murnisadar.ac.id/index.php/ Tekinkom/article/view/78.

[6] A. Ardian, I. Purnama, and V. Sihombing, "Perancangan Aplikasi Pengolah Data Siswa Berbasis Android (Studi Kasus: Mis Nurul Huda Labuhan Batu Selatan)," Pengabdi. Masy. Ika Bina En Pabolo, vol. 1, no. 1, pp. 40-53, 2019.

[7] G. J. Yanris, "Analisis Dan Implementasi Data Mining Dalam Menganalisa Kendala Akademik Yang Sering Dikeluhkan Mahasiswa AMIK Labuhanbatu (Studi Kasus: Amik 
Labuhanbatu)," Informatika, vol. 4, no. 1, pp. 15-24, 2016.

[8] V. Sihombing, "Aplikasi Simade (Sistem Informasi Manajemen Desa) Dalam Meningkatkan Pelayanan Administrasi di Kepenghuluan Bakti Makmur Kecamatan Bagan Sinembah Kab. Rokan Hilir Riau," SISTEMASI, vol. 7, no. September, pp. 292-297, 2018.

[9] W. Purba, S. Tamba, and J. Saragih, "The effect of mining data k-means clustering toward students profile model drop out potential," J. Phys. Conf. Ser., vol. 1007, no. 1, p. 12049, 2018, [Online]. Available:

http://stacks.iop.org/17426596/1007/i=1/a=012049.

[10] V. Sihombing, "Sistem Informasi Penjualan Mobil Suzuki Di Dealer Bagan Batu," SISTEMASI, vol. 7, no. 2, pp. 113-119, 2018.

[11] W. Purba, S. Aisyah, and S. P. Tamba, "Perancangan Sistem Pakar Diagnosa Penyakit Mata Katarak Menggunakan Konsep Metode Runut Mundur," JUSIKOM PRIMA (Junal Sist. Inf. Ilmu Komput. Prima), vol. 1, no. 1, 2017.

[12] V. M. M. Siregar, E. Damanik, M. R. Tampubolon, E. I. Malau, E. P. S. Parapat, and D. S. Hutagalung, "Sistem Informasi Administrasi Pinjaman (Kredit) Pada Credo Union Modifikasi (CUM) Berbasis Web," J. Tekinkom, vol. 3, no. 2, pp. 62-69, 2020, doi: 10.37600/tekinkom.v3i2.193.

[13] A. T. Purba and V. M. M. Siregar, "Sistem Penyeleksi Mahasiswa Baru Berbasis Web Menggunakan Metode Weighted Product," J. Tek. Inf. dan Komput., vol. 3, no. 1, p. 1, 2020, doi: 10.37600/tekinkom.v3i1.117.

[14] S. S. S, A. T. Purba, and V. M. M. Siregar, "Sistem Pendukung Keputusan Kelayakan Pemberian Pinjaman Kredit Menggunakan Metode Topsis Pada Cum Caritas HHKBP Pematangsiantar," $J$. Tek. Inf. dan Komput., vol. 3, no. 1, p. 1, Sep. 2020 , doi: 10.37600/tekinkom.v3i1.117.
[15] V. Sihombing, "Penerapan Multimedia Dalam Pembelajaran Di Tk Ananda Bagan Batu," J. Teknol. Inf., vol. 1, no. 2, p. 228, 2018, doi: 10.36294/jurti.v1i2.300.

[16] H. A. Simbolon and V. M. M. Siregar, "Perancangan Sistem Informasi Berbasis E-Commerce Untuk Peningkatan Penjualan Produk Jersey Olah Raga," J. Tek. Inf. dan Komput., vol. 1, no. 2, pp. 49-54, 2018.

[17] A. Budiman, U. Merdeka, J. Triono, and U. Merdeka, "Sistem Informasi Pemesanan Tiket," no. September 2016, 2017. 